\title{
Generality of differential sensitivity to alcohol in selectively bred rats
}

\author{
ELIZABETH D. WORSHAM and EARL X. FREED \\ Alcohol Research Laboratory, Lyons VA Hospital, Lyons, New Jersey \\ and Center of Alcohol Studies, Rutgers University, New Brunswick, New Jersey 08903
}

and

\author{
ELIZABETH A. LOCHRY and EDWARD P. RILEY \\ State University of New York, Albany, New York 12222
}

\begin{abstract}
The extent to which motor impairment generalizes following a $1.5-\mathrm{g} / \mathrm{kg}$ IP dose of alcohol was investigated in two lines of rats bred to be either "most" (MA) or "least" (LA) affected by alcohol. Motor impairment was assessed on several measures of general activity at approximately 60-65 days of age. MA rats were found to be significantly more impaired than LA rats in the stabilimeter and open field following alcohol, although no differences were present following saline injection. In the running wheel, activity was lower for MA as compared to LA animals following saline, although the two lines were still differentially affected by alcohol. These findings are thought to demonstrate that the disparate responses to alcohol are not unique to stabilimeter activity upon which the two lines were selectively bred, but instead indicate generalized differences in alcohol sensitivity. The utility of these lines for studying differential sensitivity to alcohol among individuals is discussed.
\end{abstract}

Animal researchers interested in developing an animal model of alcoholism or in studying central nervous system reactivity to alcohol have used selective breeding procedures to obtain certain phenotypic traits in response to alcohol. For example, Eriksson $(1968,1972)$ has selectively bred two rat strains for differences in the amount of alcohol that they selected. Mice which show a large disparity in sleeping time following a hypnotic dose of alcohol have also been reported upon extensively (e.g., Heston, Erwin, Anderson, \& Robbins, 1974; Kakihana, 1976). Additionally, Goldstein (1973) has shown that the severity of withdrawal following the establishment of alcohol dependence could be selectively bred in mice. More recently, Riley, Freed, and Lester (1976) reported on the selective breeding of two lines of rats which differ in their reactivity to a subhypnotic dose of alcohol. These two lines, designated "most" and "least" affected (MA and LA), differ in degree of motor impairment, as measured in a stabilimeter following a $1.5 \mathrm{-g} / \mathrm{kg}$ dose of alcohol. As an example of the success of this breeding program, in the ninth generation the LA

Supported by the Medical Research Service of the Veterans Administration and in part by Grant AA0067 (to E.X.F.; E.W., postdoctoral fellow). Requests for reprints should be addressed to Edward P. Riley, Department of Psychology, SUNY-Albany, New York 12222 . This research benefited by the assistance of Ms. Elizabeth Haugen. E. Lochry is a National Council on Alcoholism predoctoral fellow. animals were four times more active than MA animals in the stabilimeter despite the fact that the two groups had equivalent blood alcohol concentrations. This difference was only apparent following an injection of alcohol; the lines have shown similar baseline levels of activity following a saline injection.

The present study was concerned with the generality of this motor impairment in response to alcohol. Through the ninth generation, all testing for reactivity to alcohol occurred in the stabilimeter platform. In the present study, motor impairment was assessed following alcohol administration in these lines in two additional apparatus, the open field and running wheel. Furthermore, the time course of this impairment was examined more closely than in previous studies to aid in determining whether the disparity between groups might be due to differences in the rate of alcohol absorption.

\section{METHOD}

\section{Subjects}

Sixty-five rats (24 MA and $41 \mathrm{LA}$ ) from the second litters of the 10th generation (F10) and $33 \mathrm{MA}$ and $45 \mathrm{LA}$ rats from the first litters of the 11th generation (F11) were employed. The rats were bred at the Alcohol Research Laboratory, Lyons VA Hospital, using the same procedure described previously (Riley et al., 1976). The animals were housed two per cage and were maintained on a 12-h light-dark cycle with free access to food and water except as noted. Testing began at $60-65$ days of age.

\section{Apparatus}

Six stabilimeter platforms (Lafayette Instrument Co., 
Model A501) with incorporated electronic integrators (Acromag, Inc., Model 205 LX-1) were used to assess motor activity. The platforms were enclosed in sound-attenuating, ventilated wooden chambers, and associated programming equipment was located in an adjacent room. Open-field activity was measured in two $61-\mathrm{cm}$-diam photo activity cages (Lehigh-Valley, 145-03) in which the number of beam interruptions was automatically recorded. Lafayette activity wheels (86041), enclosed in light-attenuating boxes, were used to determine running-wheel behavior.

\section{Procedures}

Stabilimeter testing. The measurement of motor impairment in the stabilimeter has been described in detail elsewhere (Riley et al., 1976). Briefly, each animal was food-deprived for $24 \mathrm{~h}$, given a control injection of saline $(15 \mathrm{ml} / \mathrm{kg}$, IP), and immediately placed in the stabilimeter for $30 \mathrm{~min}$. The same procedure was repeated 1 week later, except that a $1.5-\mathrm{g} / \mathrm{kg}$ dose of alcohol was substituted for saline. Activity measures were recorded for each 3-min segment of the test period.

Open-field and running-wheel testing. One week following the completion of stabilimeter testing, open-field and runningwheel testing was conducted. In the F10 generation, each rat, $24 \mathrm{~h}$ food deprived, was given a $15-\mathrm{ml} / \mathrm{kg}$ IP dose of saline, placed in a holding cage for $15 \mathrm{~min}$, transferred to the open field for $6 \mathrm{~min}$, and then immediately placed in the wheel for $6 \mathrm{~min}$. The animal was placed directly into the wheel with the door closed to maximize the probability of a running response. After testing, each animal was returned to its cage for 7 days, after which the same procedure was followed with alcohol $(1.5 \mathrm{~g} / \mathrm{kg})$ instead of saline. The procedure was identical for the F11 generation, except that after each injection the animals were placed in the holding cage for only $9 \mathrm{~min}$. This slight modification was employed since the data from the F10 generation indicated that the animals were sufficiently impaired for testing within 9 min postinjection. Additionally, animals selected for breeding purposes on the basis of the stabilimeter test were excluded from open-field and runningwheel testing. Thus, only 62 animals from the F11 were tested on these apparatus.

\section{RESULTS}

Since the previous report on these two lines utilized a derived alcohol/saline ratio (ALC/SAL) to assess motor impairment, a similar procedure was employed here. The ALC/SAL score for each animal was computed by dividing the amount of activity under alcohol by the amount under saline; a ratio of 1.0 thus indicates no measurable impairment and 0.0 indicates maximum impairment. An a priori decision was made to discard animals with ratios greater than 2.0, as previous work had indicated that ratios of this magnitude were generally associated with animals who have extremely low activity rates upon initial exposure to the test chamber. Furthermore, as a lower limit of zero is set, high ratios would cause extremely skewed data. Only one F10 LA male had to be eliminated for this reason. The mean ALC/SAL ratios for each apparatus are provided in Table 1. For the stabilimeter, the ratios were calculated for the second half of the 30-min test session as this was in accord with the previous method. As can be seen, the ratios for MA animals are lower than those for LA animals regardless of the apparatus or generation. Additionally, females tended to be less impaired by alcohol than the males within each line. The significance of these trends was assessed by an unweighted means analysis of variance on the data from each apparatus within each generation, the results of which are presented in Table 2 . The effect of Line was highly significant in every case $(p<.001)$, while the effects of Sex and the interaction of Sex and Line were more variable.

The mean activity scores for each line under both saline and alcohol for each 3-min segment of the stabilimeter test session are depicted in Figure 1. Although there appear to be no group differences following saline, a large disparity is evidenced within 3 min following alcohol administration and remains throughout the $30-\mathrm{min}$ test session. An analysis of variance on these data with Line and Sex as betweensubjects factors and Drug as a within-subject factor indicated a significant Drug by Line interaction in both the $F 10$ and $F 11$ generations, $F(1,61)=29.57$, $\mathrm{p}<.001$, and $\mathrm{F}(1,74)=16.81, \mathrm{p}<.001$, respectively.

\section{DISCUSSION}

The ALC/SAL ratios in the stabilimeter are in agreement with those of previous generations. The breeding effort thus continues to be effective in maintaining the differential response to alcohol between the two lines. More importantly, these data demonstrate that the differential response to alcohol is not specific to stabilimeter activity, upon which selective breeding was based, but, rather, generalizes to other activity measures. Furthermore, the differential response is not peculiar to a single exposure to alcohol, as open-field and running-wheel data were

Table 1

Mean ALC/SAL Ratios as a Function of Line and Sex in Each Apparatus and Generation

\begin{tabular}{|c|c|c|c|c|c|c|c|c|c|}
\hline & \multicolumn{4}{|c|}{ F10 } & \multicolumn{5}{|c|}{ F11 } \\
\hline & $\mathrm{N}^{*}$ & STAB & OF & $\mathrm{RW}$ & $\mathrm{N}$ & STAB & $\mathrm{N}$ & OF & RW \\
\hline MA Males & 9 & .173 & .124 & .018 & 16 & .137 & 12 & .128 & .051 \\
\hline MA Females & 14 & .287 & .299 & .197 & 17 & .397 & 13 & .114 & .083 \\
\hline LA Males & 25 & .546 & .490 & .356 & 25 & .556 & 20 & .256 & .300 \\
\hline LA Females & 17 & .587 & .558 & .707 & 20 & .648 & 17 & .522 & .570 \\
\hline
\end{tabular}

*Two animals from the "least" affected line were not included in open field or running wheel analyses; one because of an ALC/SAL ratio greater than 2 and the other because of illness which necessitated its sacrifice. 
Table 2

The Results of Unweighted Means Analyses on Data From Each Apparatus Within Each Generation

\begin{tabular}{|c|c|c|c|c|c|c|c|}
\hline & & \multicolumn{2}{|c|}{ Stabilimeter } & \multicolumn{2}{|c|}{ Open Field } & \multicolumn{2}{|c|}{ Running Wheel } \\
\hline & & F-Ratio & df & F-Ratio & df & F-Ratio & df \\
\hline F10 & $\begin{array}{l}\text { Line } \\
\text { Sex } \\
\text { Interaction }\end{array}$ & $\begin{array}{c}21.75 \dagger \\
1.14 \\
<1\end{array}$ & $\begin{array}{l}1 / 61 \\
1 / 61 \\
1 / 61\end{array}$ & $\begin{array}{l}15.45 \dagger \\
2.36 \\
<1\end{array}$ & $\begin{array}{l}1 / 59 \\
1 / 59 \\
1 / 59\end{array}$ & $\begin{array}{c}58.76 \dagger \\
22.97 \dagger \\
2.44\end{array}$ & $\begin{array}{l}1 / 59 \\
1 / 59 \\
1 / 59\end{array}$ \\
\hline F11 & $\begin{array}{l}\text { Line } \\
\text { Sex } \\
\text { Interaction }\end{array}$ & $\begin{array}{c}21.20 \dagger \\
5.87^{*} \\
1.34\end{array}$ & $\begin{array}{l}1 / 74 \\
1 / 74 \\
1 / 74\end{array}$ & $\begin{array}{l}63.00 \dagger \\
14.00 \dagger \\
16.59 \dagger\end{array}$ & $\begin{array}{l}1 / 58 \\
1 / 58 \\
1 / 58\end{array}$ & $\begin{array}{l}55.75 \dagger \\
9.50^{* *} \\
5.78^{*}\end{array}$ & $\begin{array}{l}1 / 58 \\
1 / 58 \\
1 / 58\end{array}$ \\
\hline
\end{tabular}

${ }^{*} p<.05 \quad * * p<.01 \quad t_{p}<.001$

collected after a second exposure to alcohol.

With regard to the significant effects of Sex and the interaction of Sex and Line, particularly in the F11 generation, an effect of sex has been found in only two other generations, the F4 and F8. It is felt that the effect of sex is an artifact of the higher rates of activity shown by the females during estrous. The running wheel in particular is sensitive to the estrogenic induction of activity (e.g., Gerall, Napoli, \& Cooper, 1973; Jennings, 1969).

The activity data presented in Figure 1 show that the differences between lines is not an artifact of

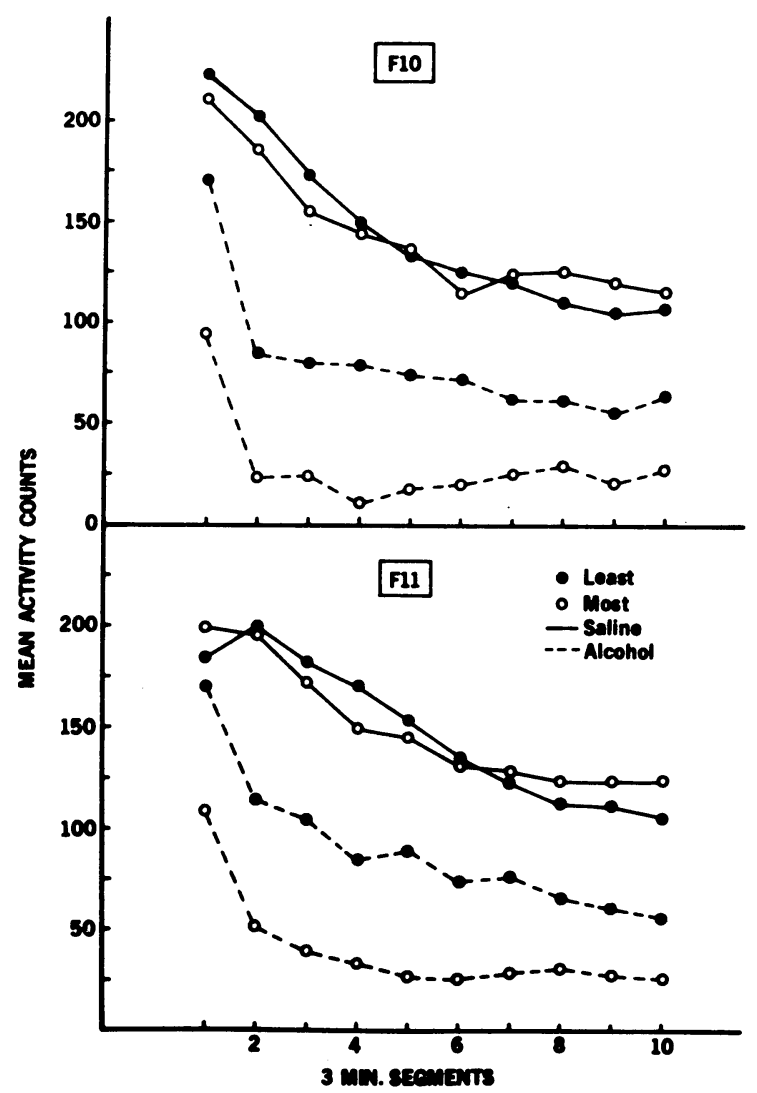

Figure 1. Mean activity scores for 3-min segments in the stabilimeter for MA and $L A$ rats following both saline and alcohol administration. higher activity rates by LA animals. LA and MA rats show comparable rates of activity in the stabilimeter following saline. However, the disparity following alcohol is evidenced soon after administration. If anything, the initial differences are greater than those later in the test session and the use of ALC/SAL ratio for Minutes $16-30$ is probably conservative. Furthermore, the group differences in open-field and running-wheel behavior were evident whether testing was begun $15 \mathrm{~min}$ (F10) or $9 \mathrm{~min}$ (F11) following the alcohol injection. These data, along with information that the two lines have equivalent blood alcohol levels (Lester, Lin, Anandam, Riley, Worsham, \& Freed, 1977; Riley, Worsham, Lester, \& Freed, 1977), indicates that the disparity is not due to the differential absorption of alcohol.

Comparable activity rates between the lines were also found following saline in the open field but not in the running wheel, where MA animals evidenced less activity than LA animals. This discrepancy in control activity in the running wheel has been found on two other occasions under both fasted and nonfasted conditions (Riley et al., 1977). While it has been suggested that wheel-running differs from other forms of activity (Baumeister, Hawkins, \& Cromwell, 1964; Collier, 1970), this still does not explain why groups bred on the basis of alcohol reactivity should show differential baseline activity in this apparatus. Riley et al. (1977) suggested that MA animals might find response-produced feedback aversive, due to a more sensitive nervous system, and hence might run less in the wheel with its greater responseassociated feedback.

Just as these lines differ in sensitivity or "initial" tolerance to alcohol, certain ethnic groups react more strongly to alcohol than others. For example, Ewing, Rouse, and Pellizzari (1974) reported that Orientals described more aversive subjective feelings following the oral administration of alcohol than Occidentals. Additionally, the Orientals showed more pronounced physiological changes such as a decrease in blood pressure and an increase in heart rate. It was suggested that ethnic differences in alcohol serisitivity may influence cultural drinking practices and alcohol's use as a physiological escape 
mechanism. These rat lines may provide a model for individual and ethnic differences in sensitivity to alcohol and help to elucidate the underlying mechanism of tolerance. In any case, these lines should have utility in animal experimentation where the heterogeneity of the response following drug administration of ten plagues researchers.

\section{REFERENCES}

Baumeister, A., Hawkins, W. F., \& Cromwell, R. L. Need states and activity level. Psychological Bulletin, 1964. 61, 438-453.

Collier. G. Work: A weak reinforcer. Transactions of the New York Academy of Sciences, 1970, 32, 557-576.

ERIKSSON. K. Genetic selection for voluntary alcohol consumption in the albino rat. Science, 1968, 159, 739-741.

ERIKSSON, K. Behavioral and physiological differences among rat strains specially selected for their alcohol consumption. Annals of the New' York Academy of Sciences, 1972, 197, 32-41.

Ewing, J. A., Rouse, B. A., \& Pellizzari, E. D. Alcohol sensitivity and ethnic background. American Journal of Psychiatry, 1974, 131, 206-210.

Gerall, A. A., NAPOli, A. M., \& Cooper, U. C. Daily and hourly estrous running in intact, spayed, and estrone implanted rats. Physiology and Behavior, 1973, 10, 225-229.

GolDSTEIN, D. B. Inherited differences in intensity of alcohol with- drawal reactions in mice. Nature (London), 1973, 245, 154-156.

Heston, W. D. W., Erwin, V. G., Anderson, S. M., \& Robbins, H. A comparison of the effects of alcohol on mice selectively bred for differences in ethanol sleep time. Life Sciences, 1974, 14, 365-370.

JeNNINGs, W. A. Estrous variations in the total behavior output of the female rat. American Zoologist, 1969, 9, 1067.

KakiHANA, R. Adrenocortical function in mice selectively bred for different sensitivity to ethanol. Life Sciences, 1976, 18, 1131-1138.

Lester, D., Lin, G., Anandam, N., Riley, E. P., Worsham, E. D., \& FreED, E. X. Selective breeding of rats for differences in reactivity to alcohol: An approach to an animal model of alcoholism, IV. Some behavior and chemical measures. In R. G. Thurman, J. G. Williamson, H. Drott, \& B. Chance (Eds.), Alcohol and aldehyde metabolizing systems (Vol. 3). New York: Academic Press, 1977, in press.

Riley, E. P., Freed, E. X., \& Lester, D. Selective breeding of rats for differences in reactivity to alcohol: An approach to an animal model of alcoholism, I. General procedures. Journal of Studies on Alcohol, 1976, 37, 1535-1547.

Riley, E. P., Worsham, E. D., Lester, D., \& Freed, E. X. Selective breeding of rats for differences in reactivity to alcohol: An approach to an animal model of alcoholism. II. Behavioral measures in the MA and LA strains. Journal of Studies on Alcohol, 1977, in press.

(Received for publication February 15, 1977; revision accepted August 22, 1977.) 